\title{
Flexible working arrangements
}

\section{Sabina Mirza}

Practice Management Consultant, British Dental Association

\section{hroughout the COVID-19 pandemic, the dental profession has had to adapt to new ways of working. From incorporating} guidance on social distancing, infection control, PPE and fallow times to implementing flexible working arrangements urgently required by staff members with parental or care-giving responsibilities. The way dental practices operate has changed.

As you look towards the end of the pandemic, challenges will continue to exist with meeting increased patient demand and NHS contractual targets and managing any adverse impact from sudden staff member absence due to self-isolation requirements, particularly as COVID-19 infections from new variants continue to soar.

This may be a good time for you to explore any opportunities for more flexible ways of working as one of the ways to meet your ongoing dental practice requirements. Many staff members too have seen benefits of flexible working during the pandemic and want to work more flexibly.

\section{What to consider before introducing flexible working}

You should start by considering what your new operational needs are during a normal working week. Are there core times/days you need certain staff to be in work? If so, which staff do you need and on which days and times? When will flexible working arrangements come into use at your practice?:

$\rightarrow$ A staff member or family member tests positive and must self-isolate

$\rightarrow$ A staff member returns from abroad and needs to quarantine

$\rightarrow$ A pregnant staff member reduces their hours in the lead up to maternity leave

$\rightarrow$ A staff member has parental or other care responsibilities

$\rightarrow$ You want to reduce staff costs in periods when the same staffing level is not required, but want to avoid making staff redundant.
What working arrangements do you want to offer or has any staff member made an application to work flexibly. There are different types of flexible working arrangements available. You could consider flexi-time, annualised hours, compressed hours, part-time hours or offering work on an 'as and when' required basis.

\section{Changes to employment contract}

Any new working arrangements implemented will cuases changes to your staff members' contracts of employment. Do the employment contracts contain a 'variation term' or 'flexibility clause' that allow you to make changes to your staff members' work hours or days of work? If so, this clause may also provide other steps you need to meet, such as how much notice you need to give and the process you need to follow before you can implement the change.

In the absence of a variation / flexibility clause, you will need to consult with the staff member and agree the changes you want to implement. Any such variation will only be lawful if both parties agree to the change. Any forced unilateral change without the staff member's consent, could be considered a breach of contract by an Employment Tribunal. The staff member could take a constructive dismissal and/or discrimination claim.

\section{Use a written agreement to document the change}

Any changes to key employment terms must be set out in writing at the earliest opportunity and, in any event, not later than one month after the change in question. This will help to ensure both parties are clear about what has been agreed and what is expected of them. When you rely on a built-in flexibility clause to make the change to your staff member's working hours, you do not need to issue a new employment contract. In all other cases the employment contract will need to be amended. This can be done by a variation letter if they are relatively few changes being made. If there are several changes being made or if there are consequential adjustments required to other terms and conditions such as pay or annual leave accrual, it is better to formalise these changes by issuing a new employment contract.

Any changes must be reasonable and justified, to avoid breaching the implied term of trust and confidence. If you implement a change to working hours, your staff member should still be paid at least the same rate of pay as before, but on a pro-rata basis. They should also get at least the same holiday and other benefits, pro rata. If you give your staff member worse terms and conditions because of the new working arrangements, they might be able to take a constructive dismissal claim.

\section{What about working arrangements} for staff members on no fixed hours?

If your staff member is not going to have a set pattern of work and no fixed working hours, then you should implement a zero-hours contract. Essentially, a zero-hours contract is where your staff member has no guaranteed hours and agrees to be potentially available for work or is obliged to accept work when offered. A staff member on a zero-hours contract is classed as a 'worker' rather than an 'employee'.

This type of contract is useful if you need a flexible workforce and where a staff member needs work flexibility around their other commitments. Where you have a zero-hours contracted worker you can opt to offer them work hours to cover any staff absence due to sickness, self-isolation, holidays instead of relying on an agency worker. Your dental practice could save paying a 'premium' via agency fees.

Where you do choose to engage zerohours contract workers, it is not enough to issue a standard contract of employment and insert contracted hours as ' 0 '. There will be a number of specific issues to be addressed and professional advice from practice management team at the BDA should always be sought in advance.

\section{Trial the flexible working arrangements} If you or your staff member do not want to agree a permanent change because you are not certain that the proposed arrangement will work, you should consider a trial period. This will give your staff member a taste of flexible working. A minimum period of three months and up to six months would be required to provide a clear picture of how well the new working arrangement works. Where changes are temporary, a review date should be agreed and the staff member informed that the review may result in normal working hours being reinstated. * 